\title{
"Addressing physician stress and burnout: impact, implications, and what we need to do"
}

\begin{abstract}
Growing levels of physician stress and burnout have reached a point where many physicians are becomingly increasingly frustrated and dissatisfied with medical practice resulting in negative attitudes and behaviors that can adversely impact satisfaction, care relationships, and outcomes of patient care. There are many factors contributing to this predicament which implies that there is no easy fix to the problem. The problem is further exacerbated by the fact that many physicians are either too busy to notice, or do not recognize the serious of the situation, or are reluctant to ask for outside help. One of the key components of success is to gain a better understanding of the physician world, listen to their concerns, and to then pro-activelyprovide appropriate support and resources to help physicians better adjust to the pressures of today's health care environment
\end{abstract}

Volume 7 Issue 4 - 2017

\author{
Alan H Rosenstein \\ Practicing Internist and Consultant in Physician Behavioral \\ Management, USA
}

Correspondence: Alan H Rosenstein, Practicing Internist and Consultant in Physician Behavioral Management, San Francisco, CA, USA, Email ahrosensteinmd@aol.com

Received: February 22, 2017 | Published: March 20, 2017

\section{Background}

It's stressful getting into medical school. It's stressful getting through the training. And it's stressful dealing with the day to day trials of medical practice. In the past physicians were able to handle all this stress as the pride and reward of delivering patient care would outweigh the time and effort required for successful care management. But the times are changing. Over the past 20years we've seen the introduction of "managed care", contract care, utilization and cost controls, and other external initiatives, all of which have reduced physician autonomy and sense of control. Now with the advent of Health Care Reform there is a greater focus on "value based care" and metric based performance accountability resulting in changing priorities and models of care all of which has left physicians bewildered as to what they have to do next to survive. Add to this the introduction of new technologies and other medical breakthroughs which have significantly increased the complexity of care making it difficult for physicians to stay on top of it all. A recent study from the Mayo Clinic reported that more than $50 \%$ of physicians report significant levels of stress and burnout. ${ }^{1}$ Several other studies have highlighted the ill effect of stress and burnout on physician satisfaction, well-being, engagement, and outcomes of patient care. ${ }^{2,3}$ So what can we do?

Purpose and Intent: We need to look at physicians as a precious resource who just want to practice good medical care. The main problem as I see it is physician awareness and their willingness to address the issue in an effective, constructive manner.

The first barrier to deal with is acknowledgement. Physicians are very dedicated and committed to their profession. They are used to the high demands, stress, and fatigue as part of the script. Getting them to self- assesses and recognize that the stress and fatigue is taking an emotional and physical toll on their well- being is a crucial first step in the process.

The second barrier is their time and willingness to do something about it. Even if they admit that they are under stress, physicians have very strong stoic egocentric personalities which prevents them from opening themselves up to outside advice. Concerns about what others may think about their competency and fears of confidentiality also inhibit their willingness to take action.

The next barrier is motivation for change. The focus here is not on the organizational benefit, it needs to reinforce the primary goal of helping the physician provide more effective rewarding care by teaching them how to handle the stress and distractions of everyday practice.

\section{Strategies}

Table one lists a number of different strategies that may be employed to help physicians deal with stress and burnout. None of the categories are mutually exclusive and in fact taking multiple approaches has added value.

One of the basic approaches is to provide additional education and training. These programs may include courses and workshops on such topics as stress management, time management, business management, or conflict management. Additional training programs on diversity training, cultural competency, harassment, and personality assessment provide additional value. Adding programs on improving work relationships by enhancing emotional intelligence, communication skills, and team collaboration techniques will also provide additional benefit. Each organization should decide on their own which services best meet their individual needs. ${ }^{4-5}$

The next area is support services. This can come from several different perspectives. Administrative and logistical support can come from reducing on-call schedules, reducing committee responsibilities, easing productivity requirements, providing documentation assistance, or through added support to help with technology issues. Clinical support can be offered through the utilization of Nurse Practitioners, Physician Assistants, and/ or Care Managers who can ease some of the routine services clinical load and enable the physician to spend more time on complex cases. Third, and most important, is to provide emotional support services.

Generic stress management and conflict management programs are useful, but the greatest gains can be achieved through individualized attention. Many organizations are offering individualized coaching or counseling sessions where trained professionals can work with physicians as to their own individual needs. These services can be offered through Wellness Committees, Physician EAPs (Employee Assistance Programs), or through available internal or outsourced resources. Physicians with more significant behavioral problems may need to be addressed by the appropriate specialty programs.

The next focus is on physician engagement. ${ }^{6}$ In order to get physicians to take action the physician needs to feel like you 
understand their world and are responsive to their needs and concerns. Engagement starts by giving the physician an opportunity for input. Input can be gathered though Town Hall meetings, Department meetings, specific task forces, or better yet, though one on one discussion sessions. Giving them a voice and an opportunity to vent their frustrations is often the first step in reducing their stress. The next important step is to be responsive to their needs. It's not that you have to solve all of their problems, but at least you can show empathy and build trust and respect around developing mutually agreeable goals and collegial relationships.

The final step is promote physician well- being. ${ }^{7}$ There is a growing amount of research focusing on the importance of physical and emotional well- being enhancing physician satisfaction, engagement, and care relationships, all of which lead to improved outcomes of care. Many organizations are now trying to improve physician well-being by offering appropriate health and wellness programs and activities and providing enhanced relaxation programs focusing on mindfulness and resilience training. ${ }^{89}$ The over-riding factor of course is to get the physician to make it a priority and set aside the time for rest and relaxation.

\section{Conclusion}

Physicians are a precious resource and we need to do what we can to help them better adjust to the pressures and complexities of today's medical practice. But we can't leave it up to the physician to take the initiative on their own. So, we need to look to the organizations in which the physician is associated with to take a pro-active role in providing encouragement and support, and to do it before a crisis occurs (Table 1).

\section{Acknowledgments}

None.

\section{Conflicts of interest}

Author declares there are no conflicts of interest.

\section{Funding}

None.

\section{References}

1. Tait DS, Omar H, Lotte ND, et al. Changes in Burnout and Satisfaction with Work- Life Balance and the General US Working Population Between 2011-2014. Mayo Clinic Proceedings. 2015;90(12):1600-1613.

2. Danielson D, Ketterling R, Rosenstein A. Physician Stress and Burnout: Causes, Effects, and Impact on Performance and Behavior. AMGA Group Practice Journal. 2013;62(3):38-41.

3. Privitera M, Rosenstein A, Plessow F, et al. Physician Burnout and Occupational Stress: An Inconvenient Truth with Unintended Consequences. Journal of Hospital Administration. 2015; 4(1): 27-35.

4. West C, Drybye L, Erwin E, et al. Interventions to Prevent and Reduce Physician Burnout: A Systematic Review and Meta-analysis. The Lancet. 2016;388(10057):2272-2281.

5. Shanafelt TD, Gorringe G, Menaker R, et al. Impact of Organizational Leadership on Physician Burnout and Satisfaction. Mayo Clin Proc. 2015;90(4):432-440.

6. Rosenstein AH. Strategies to Enhance Physician Engagement. $J$ Med Pract Manage. 2015;31(2):113-116.

7. Rosenstein A. Understanding the Psychology behind Physician Attitudes, Behaviors, and Engagement as the Pathway to Physician Well- Being. Journal of Psychology and Clinical Psychiatry. 2016;5(6):1-4.

8. Epstein R, Krasner M . Physician Resilience: What it Means, Why it Matters, and How to Promote it. Acad Med. 2013;88(3):301-303.

9. Krasner MS, Epstein RM, Beckman H, et al. Association of an Educational Program in Mindful Communication with Burnout, Empathy, and Attitudes Among Primary Care Physicians. JAMA. 2009;302(12):1284-1293 . 